\title{
$100 \%$ renewable energy system in Japan: Smoothening and ancillary services
}

\section{AUTHOR(S):}

Esteban, Miguel; Portugal-Pereira, Joana; Mclellan, Benjamin C.; Bricker, Jeremy; Farzaneh, Hooman; Djalilova, Nigora; Ishihara, Keiichi N.; Takagi, Hiroshi; Roeber, Volker

\section{CITATION:}

Esteban, Miguel ...[et al]. 100\% renewable energy system in Japan:

Smoothening and ancillary services. Applied Energy 2018, 224: 698-707

\section{ISSUE DATE:}

2018-08-15

URL:

http://hdl.handle.net/2433/259702

\section{RIGHT:}

(c) 2018. This manuscript version is made available under the CC-BY-NC-ND 4.0 license

http://creativecommons.org/licenses/by-nc-nd/4.0/; The full-text file will be made open to the public on 15 August 2020 in accordance with publisher's 'Terms and Conditions for Self-Archiving'.; この論文は出版社版でありません。引用の際 には出版社版をご確認じ利用ください。; This is not the published version. Please cite only the published version. 


\section{0\% Renewable Energy System in Japan: Smoothening and Ancillary Services}

\section{MIGUEL ESTEBAN (CORRESPONDING AUTHOR) \\ Project Associate Professor}

Graduate Program in Sustainability Science- Global Leadership Initiative (GPSS-GLI)

Graduate School of Frontier Sciences

5-1-5 Kashiwanoha, Kashiwa City, T277-8563

The University of Tokyo, Japan

Tel: 00-81-(0)80-4026-7791, ex. 64593

Email: esteban.fagan@gmail.com

JOANA PORTUGAL-PEREIRA

Centre for Environmental Policy, Imperial College London

14 Princes Gardens, London SW7 1NA, UK

Tel: +44 (0)20 75946838

E-mail: joanaportugal@gmail.com

BENJAMIN C. MCLELLAN

Graduate School of Energy Science, Kyoto University

Yoshida-honmachi, Sakyo-ku, Kyoto. Japan. 606-8501

E-mail: b-mclellan@energy.kyoto-u.ac.jp

\section{JEREMY BRICKER}

Department of Hydraulic Engineering, Delft University of Technology, PO Box 5048, 2600GA Delft, The Netherlands, j.d.bricker@tudelft.nl),

HOOMAN FARZANEH

Institute of Advanced Energy, Kyoto University, Kyoto, Japan, 611-0011

E-mail: hooman.farzaneh.2v@kyoto-u.ac.jp

NIGORA DJALILOVA

Graduate Program in Sustainability Science- Global Leadership Initiative (GPSS-GLI) Graduate School of Frontier Sciences

5-1-5 Kashiwanoha, Kashiwa City, T277-8563

The University of Tokyo, Japan

Tel: 00-81-(0)80-4026-7791, ex. 64593

Email: d.nigora@gmail.com

KEIICHI ISHIHARA

Graduate School of Energy Science, Kyoto University, Yoshida-honmachi, Sakyo-ku, Kyoto. Japan. 606-8501, ishihara@energy.kyoto-u.ac.jp

HIROSHI TAKAGI

School of Environment and Society, Tokyo Institute of Technology.

Tokyo, Japan

Email: takagi@ide.titech.ac.jp

VOLKER ROEBER

NOAA, Seattle

United States of America

Email: roeber@irides.tohoku.ac.jp 


\begin{abstract}
In the aftermath of the Paris Agreements, many countries around the globe have pledged to reduce the amount of greenhouse gas emissions being released into the atmosphere. To do so, it is important that the amount of renewable energy in the electricity grid increases, though there are worries of the capacity of the grid to cope with intermittent energy sources. To assess the feasibility of a $100 \%$ renewable energy system in Japan, the authors conducted an hourly simulation of future electricity production based on wind, solar and tidal data in Japan. The system was shown to be stable, and the authors calculated the required capacity of electrical batteries that would be necessary to balance such a system.
\end{abstract}

KEYWORDS: Renewable energy; wind, solar; electricity storage; ancillary services

\title{
1. Introduction
}

One of the most important events of recent times in Japan took place on the $11^{\text {th }}$ of March 2011, when a large earthquake offshore of its northeast region created a tsunami that went on to devastate large parts of the country's coastline 1 . The tsunami overtopped coastal defences and brought down the cooling systems at the Fukushima Dai-ichi nuclear power plan, ultimately resulting in the release of large amounts of radioactive material into the environment. As a result of this accident and other earthquake related damage, and also due to large public opposition to this source of energy [2], all nuclear reactors were shut down. The newly created Nuclear Regulation Authority (Genshiryoku Kisei Iinkai, NRA) began carrying out safety inspections and stress test assessments in 25 of Japan's existing nuclear power reactors, though it is unclear how many will eventually be brought back online. Public opinion supported by district court injunctions and prohibitive retrofitting costs are some of the major obstacles to the restart of the idle nuclear fleet. 
To compensate for the offline nuclear reactors a significant amount of fossil fuel power was brought online, which resulted in increases in the imports of natural gas and heavy fuel oil (up by $36 \%$ and $121 \%$, respectively) [3]. This has had a significant economic and environmental impact [4], given the rise in fossil fuel imports and the increase in greenhouse gas emissions. Responding to these new circumstances, the Agency for Natural Resources and Energy released an Energy White Paper detailing the country's long-term energy supply and demand plan [5]. This strategy reflects the need to guarantee a secure, economically effective and environmentally friendly energy supply, and reinforces the need to restart the country's idle nuclear fleet. Thus, there are proposals for the nuclear share in the power generation portfolio to be $20-22 \%$ by 2030 , which is equivalent to an installed capacity of the $30-35$ GW [6]. However, by 2030 only 20GW of installed capacity will be operable (considering a plant life time of 40 years) and, as earlier stated, the construction of new nuclear power plants is highly unlikely under the present conjecture of nuclear safety concerns in the country (although completion of plants currently under construction is probable). If Japan is seriously committed to achieving the Nationally Determined Contribution (NDC), ratified under the Paris Agreement, which pledges a GHG emission reduction target of 26\% below 2013 emission levels by 2030 [7, 8], an aggressive deployment of renewable energy would be required.

A number of studies in the past $[4,9-13]$ have examined future possible energy generation mixes in Japan, though these typically do not evaluate the reliability and actual feasibility of the proposed energy scenarios. Essentially, most authors simplify the analysis to yearly or monthly averages, ignoring daily and hourly supply/demand fluctuations [14, 15]. However, taking into account such fluctuations is crucial when dealing with high penetration rates of intermittent renewable energy [16], as wind strength and solar radiation patterns vary according to time, making the balancing of variable demand and variable supply more 
challenging. Statistical studies that do not take into account these geographical and periodical variations, and instead rely on country-level data, are potentially flawed. Despite this obvious flaw, to the authors' knowledge little research has incorporated such variables into the analysis of future scenarios for the case of Japan [16-19], and Heard et al. [20] found only 24 studies that have modelled $100 \%$ renewable systems in other countries (for example that in Lund et al. [21]).

Some authors believe that high penetration of intermittent renewable power sources poses a problem to traditional grid systems [22]. These grids were not originally designed to deal with sudden peaks and falls in the electricity fed into them [23], though for large grids this can be attenuated due to smoothening, as unfavourable weather conditions in one part of a country will often be compensated by better conditions elsewhere [16], and the use of storage (batteries, pumped hydro systems or hydrogen storage) and integrated transmission lines. To take advantage of the smoothening effect it is essential to have an efficient long-distance transmission grid and to employ smart-grid technologies with controllable demand and supply. More accurate models should include the analysis and study of geo-physical variables on an hourly basis (or ideally a minute-by-minute basis if data and computing power are available). Examples of long-distance transmission can already be found elsewhere, for instance, the Netherlands transmits its surplus electricity to Norway, where it is used to power hydro pumped storage systems [24] or in Brazil, with the world's longest transmission link (2400 $\mathrm{km}$ ), which connects the Northeast hydropower plants with the large power demand in the South-Central region .

The creation of a low impact energy sector in Japan will probably require the use of electric storage and smart-control technologies [25-28]. A number of different possible systems have been envisaged, such as the use of PV generation with various types of batteries, or wind 
power and hydrogen [29-33]. For the case of Japan, it has been estimated that around 40TWh of storage would be needed to compensate for the extra energy that was required to power air conditioning units in the summer, though a system that uses only solar, wind, hydroelectricity and biomass is likely to have trouble meeting demand [34]. However, it is worth noting that after 2011 a number of power saving strategies have been implemented in Japan during the summer months [35], resulting in about $15-20 \%$ decrease in the electricity demand during this period.

Heard et al. [20] pointed out that in order to be feasible, a 100\% renewable energy system must meet four different criteria:

1. Criterion 1: The electricity demand to which supply will be matched must be projected realistically over the future time interval of interest

2. Criterion 2: The proposed supply of electricity must be simulated/calculated to be capable of meeting the real time demand for electricity for any given year, together with an additional back-up margin, to within regulated reliability limits, in all plausible climatic conditions

3. Criterion 3: Any transmission requirements for newly installed capacity and/or growth in supply must be described and mapped to demonstrate delivery of generated electricity to the user network such that supply meets both projected demand and reliability standards

4. Criterion 4: The proposed system must show how critical ancillary services will be provided to ensure power quality and the reliable operation of the network, including distribution requirements

These authors note how to date no literature on the subject has completely addressed such criteria, noting how the only study in Japan on their list (that of Esteban et al. [36]) fails to discuss Criterions 3 and 4 altogether, and even the best ranking studies in their list (by the 
Australian Energy Market Operator [37]) also fail to significantly discuss it. Thus, in the present work the authors set out to try to ascertain as to whether a $100 \%$ renewable energy system in Japan could be feasible from the point of view of transmission and the provision of ancillary services. Given that Heard et al. [20] claim that no study satisfied their four criteria, the originality of the present work lies precisely in showing that it is possible for a scientific study to satisfy all of their criteria, and prove that a $100 \%$ renewable energy system can work.

To do so, the study modifies and updates the methodology of Esteban et al. [36], (which considers only solar and wind power) to encompass other types of intermittent energy, in this case ocean energy technologies. The model simulates future electricity production based on the actual historical hourly wind, solar and tidal data (for a sample historical year in the past), and attempts to ensure that electricity demand in the year 2030 can be met. Other non-intermittent technologies, such as hydropower, biomass and geothermal are also included in the simulation. The model will then be used to calculate how the provision of ancillary services could work for the systems proposed.

\section{Criterion 1: Projection of Future Electricity Demand}

Heard et al. [20] are satisfied that the system described by Esteban et al. [36] adequately meets their minimum requirements for this criterion. This section summarises the projections for future electricity for the present model, and the assumptions on which they are based, following Esteban et al. [36].

\subsection{Current Japanese electricity mix and future demand}

The country currently consumes around 990 TWh of electricity per year, though this is likely to be significantly influenced by future socio-economic and demographic changes, as well as 
changes in technology uses and efficiency. Even before the 2011 earthquake the power generation matrix in Japan was heavily dependent on fossil fuel technologies, which produced $64 \%$ of the electricity used in the country [38], with renewable sources (mostly in the form of hydropower) representing only around $10 \%$ of the energy [38]. After the events of 2011 the Japanese government initiated a series of policies aimed at reforming the electricity sector, diversifying the electricity mix and encouraging independent producers. One of these is the establishment of a Feed-In Tariff (FiT) system for renewable electricity suppliers [18, 39, 40], with initially high tariffs which have slowly been falling [41]. As a result, domestic shipments of solar modules increase by $171 \%$ between 2011 and 2012, and in 2016 there were $42.8 \mathrm{GW}$ of solar power installed in Japan, with approved significant amount more in the pipiline [42].

\subsection{Population decline}

To estimate future levels of electricity demand it is necessary to take into account population change. The fertility rate in Japan has fallen below the level necessary to maintain a stable population, and the overall population of the country has already started to decline. The Japanese National Institute of Population and Social Security Research [43] has forecast that by 2030 the population will have decreased to around 117 million (from the present 127 million). Although there are likely to be many regional variations (given that rural areas are experiencing more pronounced declines than major cities [44], where the population remains stable), the present work will assume the rate of depopulation to be identical within regions $[45]$.

\subsection{Estimation of Japanese GDP and electricity consumption scenarios by 2030}

For the last two decades Japanese GDP growth has been mostly flat (possibly as a consequence of the stagnating/decreasing population), and according to the Japan Centre for 
Economic Research GDP annual growth rate per capita is forecast as $0.2 \%$ between 2016 and 2025 [46]. Future electricity demand is thus likely to be mostly affected by the demographics of the country and the possibility of a large scale uptake in the use of electricity vehicles or other technologies.

As such, for the simulations in this study, the authors used four different demand scenarios (summarised in Table 1):

-Scenario A. Reduction in demand to $60 \%$ of its current level, following Tsuchiya [19], meaning a total production of 594TWh per year. The rationale for this would derive from incremental future increases in energy efficiency, a decrease in the population, and an almost negligible use of electric vehicles by 2030 .

-Scenario B. 33\% decrease in current electricity demand by 2030, due to the extensive use of electric vehicles. Following the work outlined in [4], in which the authors forecast the overall aggregated electricity demand in 2030 as a product of the estimated electricity demand per capita and the predicted population around this time. Essentially, per capita electricity demand was estimated by fitting a multiple regression on historical data from 1980 to 2010, using GDP per capita, and industrial and residential price of electricity as predictors of per capita demand. Thus by the year 2030 the total yearly electricity demand is forecast to be $823 \mathrm{TWh}$, in line with [4].

-Scenario C. This is a scenario that assumes that the electricity demand in Japan would stay the same as that at present (i.e. $990 \mathrm{TWh}$ ).

-Scenario D. This is similar to the energy scenario used by Esteban et al. [36], estimating that energy demand will stay the same, but that electrification ratios will greatly increase [46]. Essentially, this would mean that total demand would be 1.5 times higher than that in 2005 , 
and would rise from $990 \mathrm{TWh}$ in 2005 to $1400 \mathrm{TWh}$ in 2030. This scenario would appear extreme, given the demographic scenarios presented earlier [44], though there is always the (remote) possibility that the government will change its long term stance on migration and allow a greater influx of immigrants into the country.

Table 1. Summary of demand scenarios

\begin{tabular}{|c|c|c|c|}
\hline Scenario & $\begin{array}{l}\text { Change in } \\
\text { Electricity Demand }\end{array}$ & $\begin{array}{l}\text { Total Electricity } \\
\text { Demand (TWh/year) }\end{array}$ & Reference \\
\hline A & $-60 \%$ & 594 & [19] \\
\hline B & $-33 \%$ & 823 & [4]) \\
\hline $\mathrm{C}$ & No Change & 990 & - \\
\hline D & $+150 \%$ & 1440 & {$[36,46]$} \\
\hline
\end{tabular}

\subsection{Fluctuations in energy consumption}

Japan has three climate zones, though much of it is classified as "humid subtropical" with four distinct seasons, and there is a substantial fluctuation in the patterns of electricity consumption between them, as shown in Figure 1. Electricity consumption peaks in winter (due to heating requirements) and in summer (due to the high usage of air-conditioning units), and the annual load factor is currently approximately $60 \%$ on average, (rather low compared with $70 \%$ to $80 \%$ in Europe [47]). On top of these long-term seasonal variations, there are also short-term fluctuations between daytime and night time [16].

The required electrical load for each hour of the day in the year 2030 was derived from using historical demand for the year 2015 (see Figure 1), and scaled to the year 2030 (see [48]), using data obtained from the Federation of Electric Power Companies of Japan [49]. This scaling up (or down) of the electricity demand was conducted linearly. In other words, it was 
assumed that the overall pattern of the electricity demand throughout the day will stay constant.

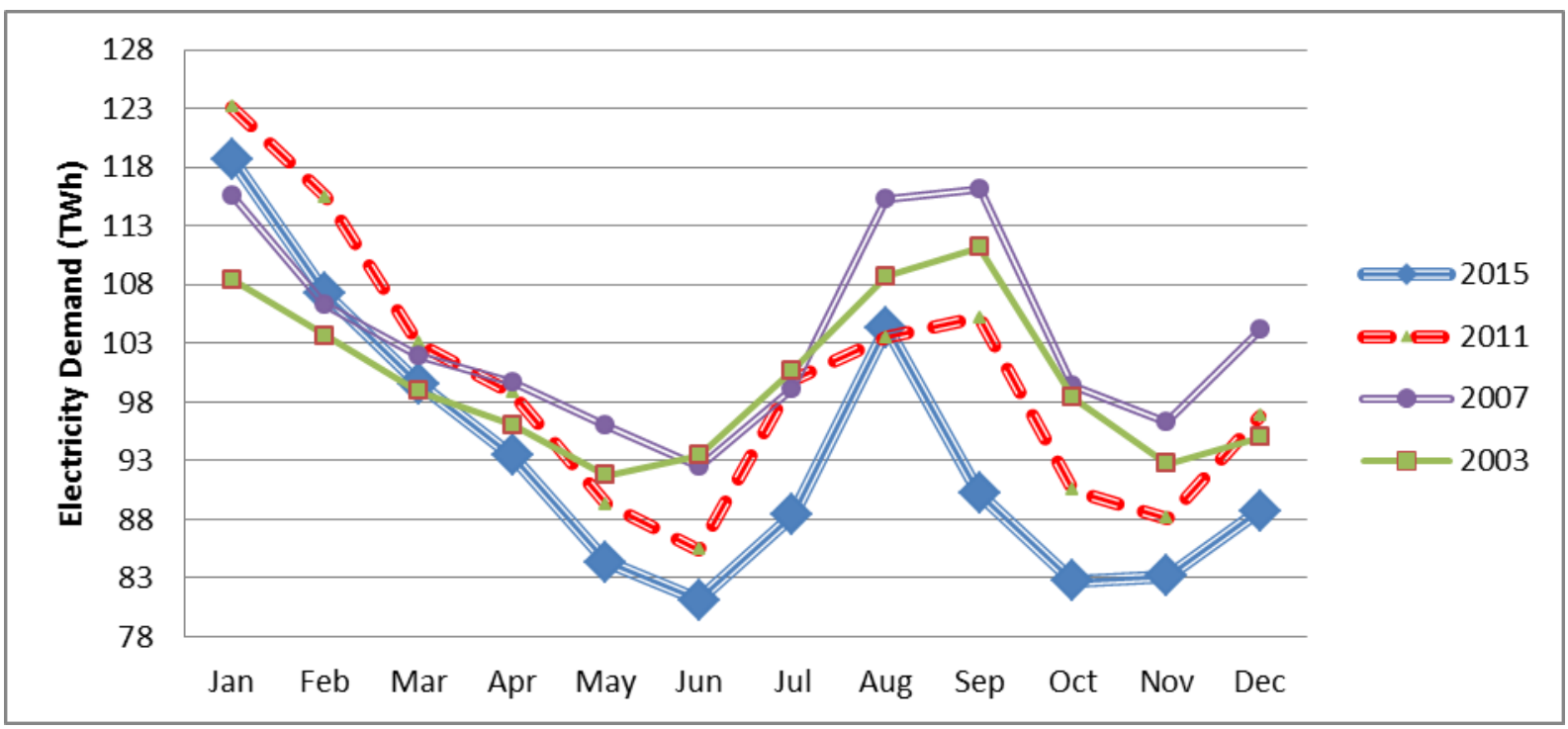

Figure 1. Trends in electricity demand in Japan between 2003 and 2015

3. Criterion 2: Methodology used must ensure real-time demand can be met, by using plausible real-time data on weather and ocean conditions

Heard et al. [20] emphasize how a future $100 \%$ renewable electricity system must have high reliability (>99.9\%), meaning that it must ensure a constant (i.e. available at all times and/or fully dispatchable (able to be called-up or withdrawn at any time in response to demand changes) supply of electricity).

\subsection{Methodology outline, and reliability of the overall system}

To ensure that such a system could be realized, the authors improved on the methodology of Esteban et al. [36], by expanding the types of energy sources considered (most notably through the inclusion of ocean energy technologies). Essentially, this method uses historical meteorological and ocean data to estimate the amount of energy that can be produced by a variety of energy devices, be it solar panels or wind or tidal turbines (see Tables 2 and 3). 
The methodology takes as input meteorological data (wind speeds, solar irradiation and tidal currents) at a number of stations distributed throughout the territory of Japan. It was assumed that solar panels would be mostly installed in cities and their vicinity, and the 15 biggest cities in Japan were considered. Wind power was assumed to follow current patterns of distribution, clustered around 24 existing wind farms. The eight straights with best tidal resources were considered for tidal energy.

The energy produced by intermittent sources using the real meteorological data during each hour of each day was then checked against total demand, as shown in Table 2. If solar, wind and ocean power were unable to provide for the electricity demand, the simulation then started to access other types of energy sources to balance demand. In the first instance it will resort to geothermal, then hydropower, then biomass, and finally to hydro pumped-storage. Finally, the energy stored in batteries will be used, if the system cannot produce enough electricity.

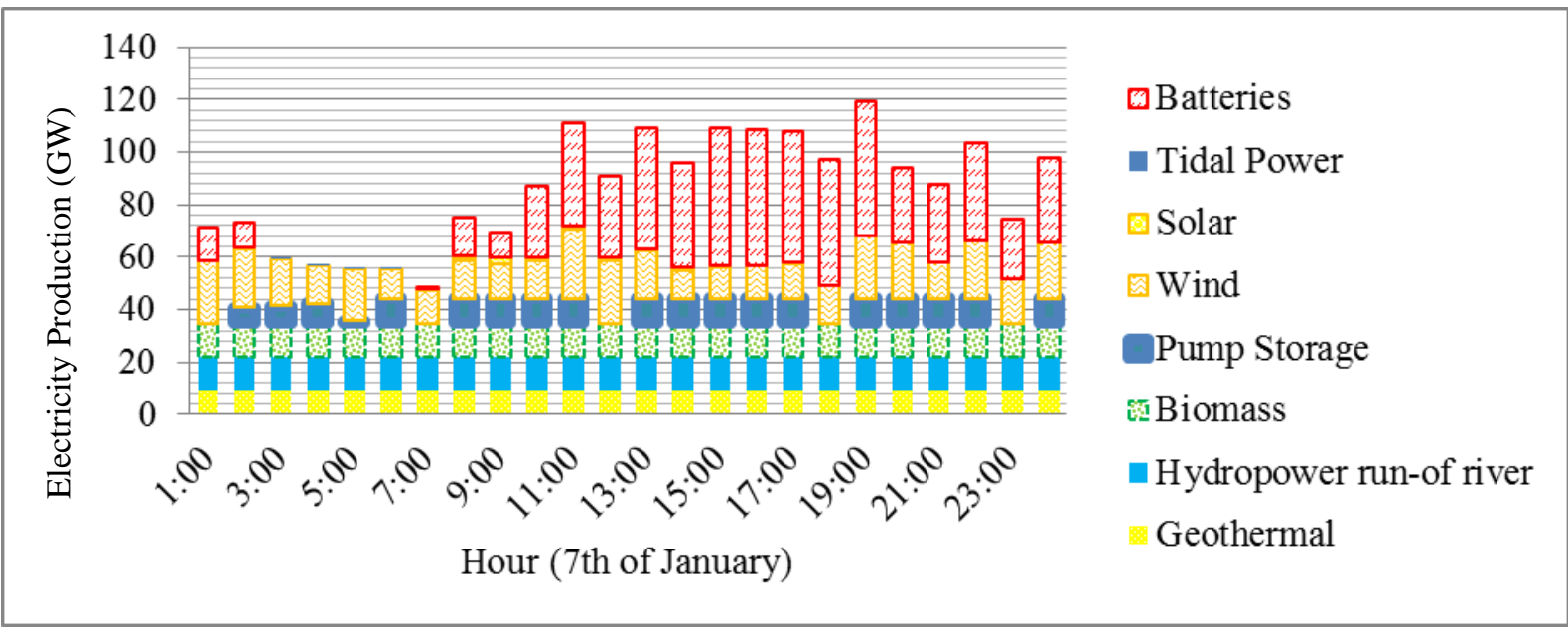

Figure 2. Sample of one generation day (Energy Scenario A, for a $\Psi=31 \%, 68 \mathrm{GW}$ solar and 154GW wind). Batteries are charged during periods when the demand for electricity is lower than the supply (typically at night, or on days when production is high. This figure represents a day in which power from wind and solar is limited, meaning that much of the load comes from pumped storage and batteries) 
The electricity produced by solar panels in a given hour is given by the equation:

$$
P_{S}=I \times \eta \times F_{\text {temp }} \times F_{i n v} \times F_{\text {other }}
$$

where $I$ is the irradiance $\left(\mathrm{kW} / \mathrm{m}^{2}\right), \eta$ is the conversion efficiency of the solar panels, and $F_{\text {temp }}$, $F_{i n,}, F_{\text {other }}$ are the efficiencies of the temperature, inverter and other factors, respectively. The values of these parameters are summarized inTable 2 .

The electric power delivered at any one given hour, $P_{W}$, by a wind turbine is considered to depend on wind speed, and can be expressed by the following set of equations:

$$
\begin{array}{ll}
P_{W}=R_{C W} \frac{V^{k}-V_{C}^{k}}{V_{R}^{k}-V_{C}^{k}} & \text { for } V_{C} \leq V \leq V_{R} \\
P_{W}=R_{C W} & \text { for } V_{R} \leq V \leq V_{F} \\
P_{W}=\mathrm{O} & \text { Otherwise }
\end{array}
$$

where $V$ is the actual wind speed at the turbine, $k$ a factor depending on the shape of the curve shown in Fig. 3, $R_{C W}$ is the rated output power, $V_{C}, V_{R}$ and $V_{F}$ are speeds for cut-in, rated and cut-off. A summary of the parameters used is given in Table 3.

The time averaged power density $P\left[\mathrm{~W} / \mathrm{m}^{2}\right]$ available in a tidal regime can be approximated by

$$
P=\frac{1}{g} \rho K_{g} K_{n} U^{B}
$$

where $\rho$ is water density $\left(1020 \mathrm{~kg} / \mathrm{m}^{3}\right), U$ is maximum flow speed, $K_{s}=0.424$ is a velocity 
shape factor for sinusoidal flow, and $K_{n}=0.57$ is a spring-neap factor (which assumes that maximum neap current speed is $60 \%$ of maximum spring current).

For solar and wind, the data from AMeDAS (Automated Meteorological Data Acquisition System of the Japan Meteorological Agency) [49] for the year 2001 was used. Data for the strength of the tidal flows was obtained from NOWPHAS for the year 2001. Throughout all the simulations carried, the authors calculated the reliability of the system, in terms of it being able to service the demand, to ensure that a reliability $>99.9 \%$ could be achieved (as per the criteria set-out by Heard et al. [20]).

It is important to note that the current system uses hourly weather data, and the authors contend that this is appropriate to study a given area. While Heard et al. [20] emphasize that one-hour timescales will not account for rapid fluctuations in solar photovoltaic output, the authors would like to emphasize that any quick variations induced by the passage of clouds would be smoothened out over a city and regional scale. Moreover, once grid parity is achieved by solar PV, it is likely that FiTs will disappear, and thus the electricity produced will be used directly by households, commerce and industries, and only surplus electricity will be sold to the grid. Hence, small timescale fluctuations will be dealt with by battery systems installed close to the PV units, and thus taking into account such small timescale variations is unnecessary.

\subsection{Solar and wind composition scenarios}

A number of different mixes of solar to wind scenarios were run. Esteban et al. [16] calculated that the optimum solar to wind installed capacity for a system that had the maximum load during summer months had a mix $\Psi$ of $31 \%$ :

$$
\psi=\frac{R_{C S}}{R_{C W}+R_{C S}}
$$


where $R_{C S}$ is the total installed rated capacity of all solar panels and $R_{C W}$ the installed rated capacity of all wind turbines.

However, given recent gains in efficiency and energy saving, electricity usage now peaks during winter months, making such a system less advantageous. Thus, a system with an equal nominal wind and solar installed capacity, and one with high penetration of wind power, were also analysed. These scenarios will be referred to as the high wind ( $\Psi=31 \%)$, balanced $(\Psi=50 \%)$, and high solar $(\Psi=69 \%)$ scenarios.

\subsection{Location of solar, wind and ocean energy devices}

The method simulates the production of energy at a variety of points ("farms") in Japan, taking into account the climatic/tidal conditions at each point (see Esteban et al., [16] for more details). "Solar farms" were considered to be installed on the rooftops of major population centres, and the weather conditions of 15 of the 47 prefectural capitals in Japan were used to simulate generation. The conversion efficiency was assumed to be $20 \%$, as outlined in Table 2 [16]. "Wind farms" were considered to be located in the areas where they are currently located, and thus future scenarios represent a "scaling-up" of these farms. However, an allowance is also made for other wind farms to be located close to regional capitals and "solar farms", so these areas also form part of the potential future wind farms, with a total of 24 wind farms being considered. The maximum rated capacity of wind turbines was set at 10MW, see [16]), as shown in Table 3. For the case of "tidal farms", the methodology outlined in Bricker et al. (2017) was used, which can estimate the amount of electricity that could be produced at the most promising tidal straits in Japan. However, at present it appears that this resource is rather limited, and as such only the most promising sites identified in Bricker et al. [51] are used (see Table 4). 


\subsection{Non-intermittent renewable energy resources}

If intermittent sources cannot cover electricity demand, the simulation will then start to access other types of energy sources. For the case of pump-storage the installed capacity was set as 19.4 GW and the maximum storage capacity would be 1.2 PJ [21]. This is basically the same as current capacity, so the assumption is that no new pumped-storage would be built. Conventional hydropower would stay constant, with no new dams built. The capacity factors and installed capacity of each of these types of units is outlined in Table 4.

\subsection{Balancing the system through electricity storage (batteries)}

If, after using all these sources the system still cannot meet demand, then the electricity from the batteries of electric cars is accessed. Different scenarios regarding the total size of the battery pool were calculated, and for reference it is useful to consider than a Tesla S76 model has a battery of $67 \mathrm{kWh}$, meaning that 22.68 million of these cars would have a storage capacity of $1,520 \mathrm{GWh}$.

The transmission capacity from batteries to grid and vice versa was assumed to be high, at around $120 \mathrm{GW}$, as in many cases the batteries would only be used to directly power appliances within a house. The conversion (round-trip) efficiency of batteries was assumed to be 90\% [19], with Error! Reference source not found. showing an example of the simulation providing for demand for one sample day. 
Table 2. Assumed characteristics of solar cells in the year 2030 [51]

\begin{tabular}{|l|c|c|c|}
\hline Parameter & Symbol & Value & Unit/Notes \\
\hline Peak power of solar cells & $R_{C W}$ & 0.5 & $\mathrm{~kW} / \mathrm{m}^{2}$ \\
\hline Conversion efficiency & $H$ & $20 \%$ & \\
\hline Efficiency of inverter & Finv & $95 \%$ & \\
\hline Efficiency for other factors & Fother & $95 \%$ & \\
\hline Efficiency at low Temperature & Ftemp & $90 \%$ & Dec-Feb \\
\hline Efficiency at moderate Temperature & Ftemp & $85 \%$ & Mar-May \& Sep-Nov \\
\hline Efficiency at high Temperature & Ftemp & $80 \%$ & Jun-Aug \\
\hline Azimuth angle & & 0 & Degrees \\
\hline Inclination to horizontal of solar panel & & 30 & Degrees \\
\hline
\end{tabular}

Table 3. Characteristics of wind turbine units in 2030 [52]

\begin{tabular}{|l|c|c|c|}
\hline Parameter & Symbol & Value & Unit \\
\hline Rotor Diameter & $d_{r}$ & $120-150$ & $\mathrm{M}$ \\
\hline Cut-in Speed & $V_{C}$ & 3 & $\mathrm{~m} / \mathrm{s}$ \\
\hline Rated Speed & $V_{R}$ & 10 & $\mathrm{~m} / \mathrm{s}$ \\
\hline Cut-out Speed & $V_{F}$ & 30 & $\mathrm{~m} / \mathrm{s}$ \\
\hline Air Density & $\rho_{a}$ & 1.205 & $\mathrm{~kg} / \mathrm{m}^{3}$ \\
\hline Rated capacity & $R_{C W}$ & 10 & $\mathrm{MW}$ \\
\hline
\end{tabular}


Table 4. Capacity Factor complementary types of energy sources [53]

\begin{tabular}{|l|l|l|}
\hline Energy type & Capacity Factor (\%) & Installed Capacity (GW) \\
\hline Hydropower & $45 \%$ & 27.6 \\
\hline Tidal Power & Depends on farm & 0.67 \\
\hline Biomass & $80 \%$ & 15.9 \\
\hline Geothermal Power & $80 \%$ & 11.8 \\
\hline Pumped Storage & $48 \%{ }^{1}$ & 19.8 \\
\hline
\end{tabular}

\subsection{The Impact of Extreme Climate Events}

Heart et al. [20] mention that it is necessary for a 100\% renewable energy system to address the impact of extreme climate events. For the case of the Japanese electricity grid, it is clear that there are considerable risks facing any energy system [18], given the large potential for natural disasters in the country (be they earthquakes, tsunamis, typhoons or volcanic eruptions). Given such constraints, which are perculiar to the case of Japan, and the experience of the 2011 event, it is likely that a $100 \%$ renewable dispersed system would be more reliable than a centralised system that could be more easily disrupted by impacts to several power plants [12]. Given such issues and the need for redundant capacity to cope with disasters, it is unlikely that any transitory weather anomaly would be likely to disrupt the system more than when all of the 54 nuclear reactors in the country were brought offline as a consequence of the 2011 Tohoku Earthquake and Tsunami.

\section{Criterion 3: Transmission for Newly Installed Capacity}

As outlined earlier, the present simulation assumes that the electricity produced by PV will be consumed (to a large extent) by those who are producing it, as it would be installed mostly in

\footnotetext{
1 Note: This value is the efficiency of an unmodified Pump-as-Turbine (PAT). The roundtrip efficiency of pumped storage is typically $\sim 75 \%$ for a reversible pump/turbine, and $>80 \%$ for separate, dedicated pump and turbine.
} 
the rooftops of houses or businesses. Excess production would be stored in batteries in the vicinity, making use of the distribution network. Eventually, any excess capacity would be distributed to other cities, using the transmission grid. However, given that most electricity would be consumed close to the point of production, it is expected that the requirements placed on the grid would be modest. The challenge comes from the integration of large amounts of wind power into the system, which would mostly be centred around the northern parts of the country. This is likely to require the upgrading of some parts of the transmission grid, and it might be necessary to create a low-loss transmission line that connects Aomori and Hokkaido to the highly densily populated areas around Greater Tokyo (with a population of around 36 million, it is expected that much of the battery storage capacity would be concentrated in this area). The overall distance of such a line would be in the range of $700-1,000 \mathrm{~km}$, and well within the limits of what the Japanese government could afford.

\section{Criterion 4: Provision of Ancillary Services}

Japan has two different grid systems, which generate electricity at either 50 or $60 \mathrm{~Hz}$, with a minimal degree of connection between them. The frequency of both systems would have to be maintained close to the prescribed standards in any future grid, a job that currently is provided by the inertia of "synchronous" generators, where electricity is generated through turbines spinning in unison at close to the regulated standard (Heard et al. [20]. Wind and solar PV do not currently provide such frequency-control ancillary services [37], and the increase in intermittent renewable generation is already leading to a scarcity of support services, increasing the risk of breaching reliability standards [20].

In this section the authors will explore the average and minimum synchronous capacity of each of the demand and energy mix scenarios. To do so, the authors have considered that 
hydropower, biomass, geothermal and pumped storage are the only types of energy that can provide these ancillary services.

\subsection{Scenarios A and B: Reduction in future electricity demand}

The amount of required solar and wind capacity in the system (assuming that all other types of energy plant remain constant, as shown in Table 4) is influenced by the amount of electric battery storage, as shown in Fig. 2 (for scenario A, representing a decrease in electricity use and no electric vehicles, all the batteries would essentially be installations dedicated exclusively to balancing the power system). Essentially, the higher the total storage capacity of batteries, the lower the overall required installed capacity of solar or wind, as more electricity during periods of good atmospheric conditions can be stored and used later on (see Figs 3 and 5). Any electricity that cannot be stored is essentially dumped, which will be represented in later figures as "wastage". Note that the system transfers unused electricity into the batteries during times of high production of electricity from intermittent sources, which can then be returned to the grid when conditions are not as conducive to the production of electricity (with Fig. 2 showing one such period). Overall, given that the peak in electricity use is during winter, high wind scenarios appear more interesting than high solar scenarios, as during winter solar radiation is weaker (Figs 3 and 5).

It is interesting to note that the installed capacities shown in Scenario A are not significantly different to what has already been planned in Japan for the case of solar (Fig. 3), though they would require a significant increase in wind penetration. However, the picture is very different for the case of Scenario B, with the required capacities significantly larger than what is currently planned (Fig 5). Also, for this case a significant amount of electricity production is wasted, which could be almost up to $30 \%$ of production for the lower battery scenarios (Fig. 6). Essentially, once the batteries are fully charged, any additional production from intermittent sources would be wasted, which would clearly have an effect on the overall 
profitability of such as system. Further increases in battery storage only seem to slowly reduce this problem, and it would probably be advantageous to use a different long-term storage mechanism, such as hydrogen, to overcome this problem.

In terms of the synchronous capacity in the system, scenario A scores quite well, with average values of around $50 \%$ or higher. The minimum amount of electricity produced from synchronous sources at any one point in the year is approximately one third of all electricity produced. This drops noticeably for the case of scenario B, with a minimum generation of power from synchronous sources of around 25\% (See Fig. 4).

\subsection{Scenarios $C$ and $D$ : No change or increase in future electricity demand}

Scenario $\mathrm{C}$ represents an artificial scenario that would assume everything stays the same as present conditions, and that overall energy consumption throughout the year would stay at $990 \mathrm{TWh}$. This would require the installation of far more solar power than is currently planned. For the high solar scenarios Figure 7 shows how this could be between $411 \mathrm{GW}$-for a higher range of installation of battery storage of $13,780 \mathrm{GWh}$ - to $659 \mathrm{GW}$-for a lower range of batteries of $1,520 \mathrm{GWh}-$, which would be 4 to 6 times what is currently installed or approved in Japan. This does not seem entirely realistic, though the expansion on wind power required would be significant, at between $187 \mathrm{GW}$ to $300 \mathrm{GW}$. This is still plausible, as several countries around the world (China, USA or Germany) have installed total capacities that are in those orders of magnitude (Germany has in excess of 50GW, the USA has over 80GW and China over 168GW). Nevertheless, the challenge would be significant, given Japan's comparatively inferior wind resources, and could require the use of significant amounts of wind turbines around the northern parts of the country. More serious would be the drop in synchronous power generation, which would reach yearly minimums of just over $20 \%$, as shown in Figure 8. Energy wastage would be significant for the low battery storage 
scenarios (42\% for an installed battery storage of $1,520 \mathrm{GWh}$, as shown in Figure 8), and to be financially viable would inevitably required large amounts of batteries to be installed. Wastage can be reduced to under $10 \%$ for the higher battery storage scenarios shown in Figure 8 , but the reduction in wastage gradually flatlines, indicating how introducing extra batteries gradually has less influence on the reduction of wastage. The calculation of the cost optimization of the system is outside of the scope of this paper, but it is clear that there would be a point where the reduction of electricity waste would no longer be justified by connecting more batteries into the system, and that this issue needs to be carefully analysed in the future.

Scenario D estimates that electrification ratios will greatly increase, and that total demand would be 1.5 times higher than that in 2005, and would raise from 990 TWh in 2005 to 1400 TWh in 2030. For this scenario, it is clear that a significant amount of batteries would be needed, or otherwise a completely unrealistic amount of installed wind and solar PV capacity would be required (see Figure 9), and wastage would become a significant problem (Figure 10). For the highest battery storage scenario considered, the high solar scenario would require $787 \mathrm{GW}$ of solar PV (almost 8 times that currently installed or in planning), and $358 \mathrm{GW}$ of wind (which is around 2 orders of magnitude higher than that currently installed). Clearly, the challenge in implementing such a system would lie in the feasibility of the wind power component of the system, which would hinge on whether floating wind turbines and more powerful turbines can be developed. Current developments in the field indicate that this is unlikely to be a problem, though it appears likely that the implementation of the solar requirements of the system would come about earlier than wind. Nevertheless, even considering a high amount of batteries, wastage is likely to become a significant problem (accounting for around $20 \%$ of electricity generation, depending on the scenario and amount of batteries), with average synchronous capacity at only around $20 \%$ and minimum around $15 \%$. Such scenarios would clearly mean that significant changes would have to be made to the grid distribution and consumption system, requiring the use of smart grid technologies. 


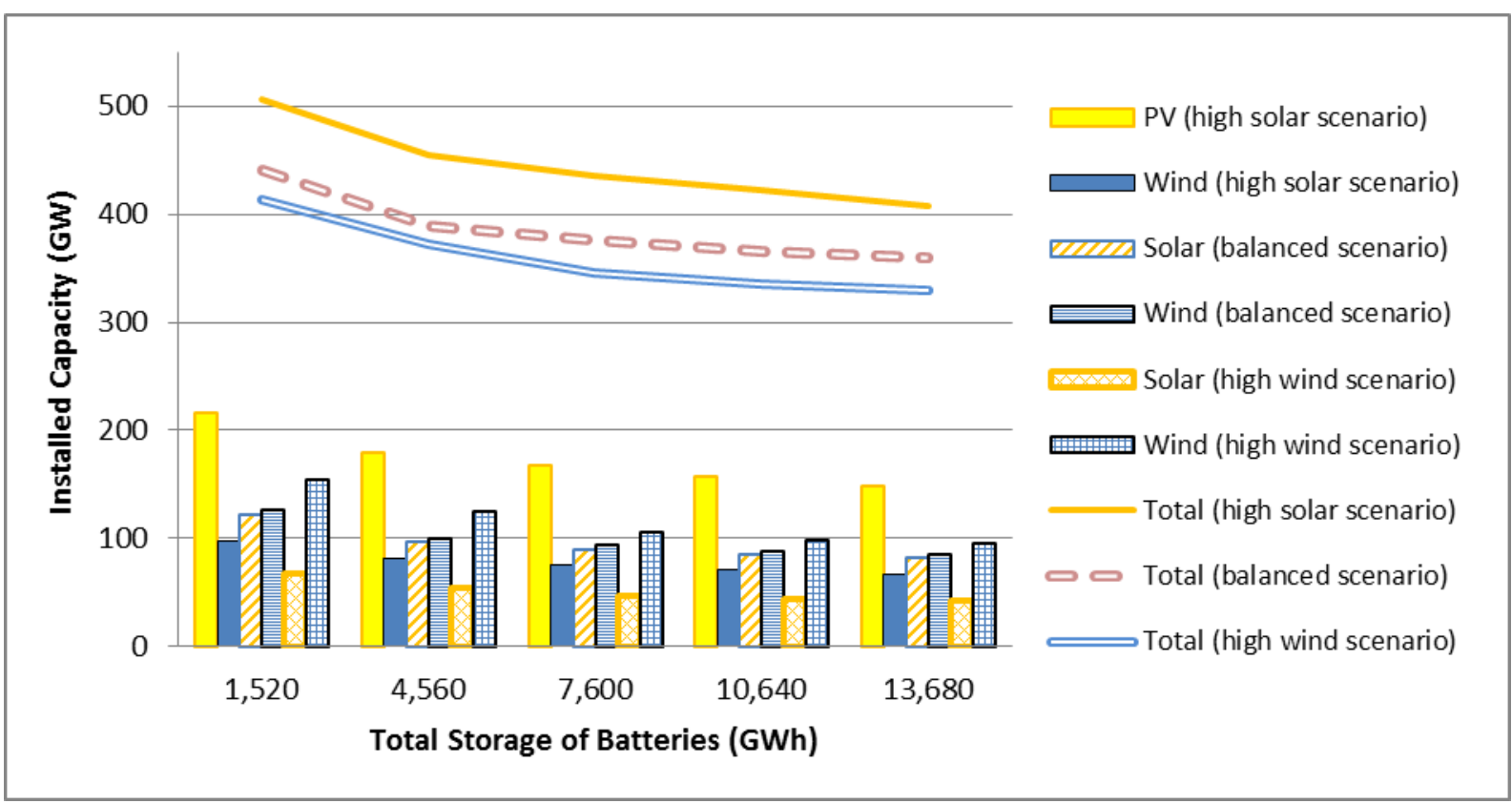

Figure 3. Required solar and wind installed capacity for energy demand scenario A (60\% reduction in overall electricity use), for different storage capacities.

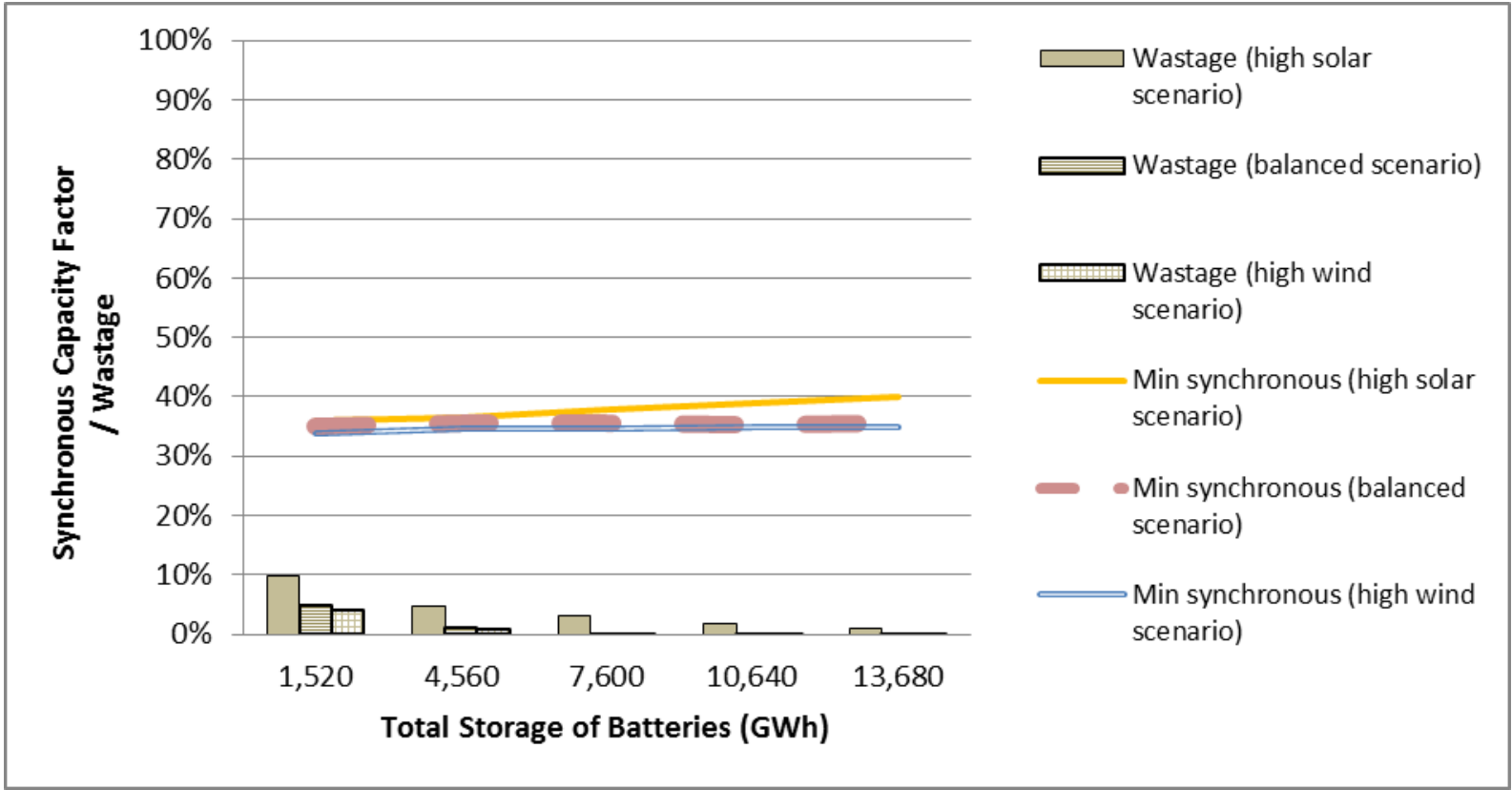

Figure 4. Average synchronous capacity and electricity wastage as a percentage of production for energy demand scenario A. The minimum synchronous generation that would be achieved if all renewable energy resource turbines were run in "synchronous condenser mode" is also shown 


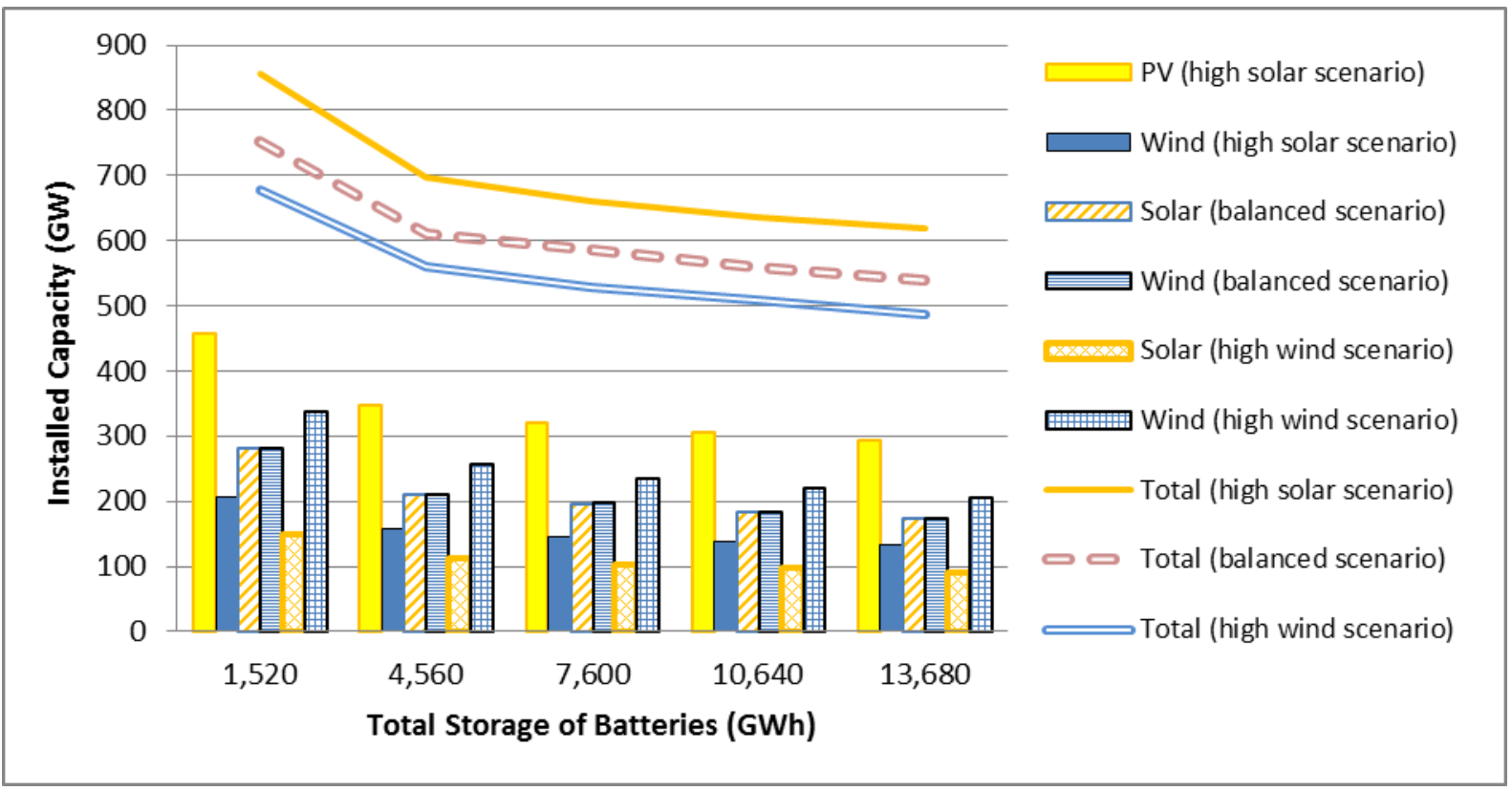

Figure 5. Required solar and wind installed capacity for energy demand scenario B (full electrification of transport system), for different storage capacities.

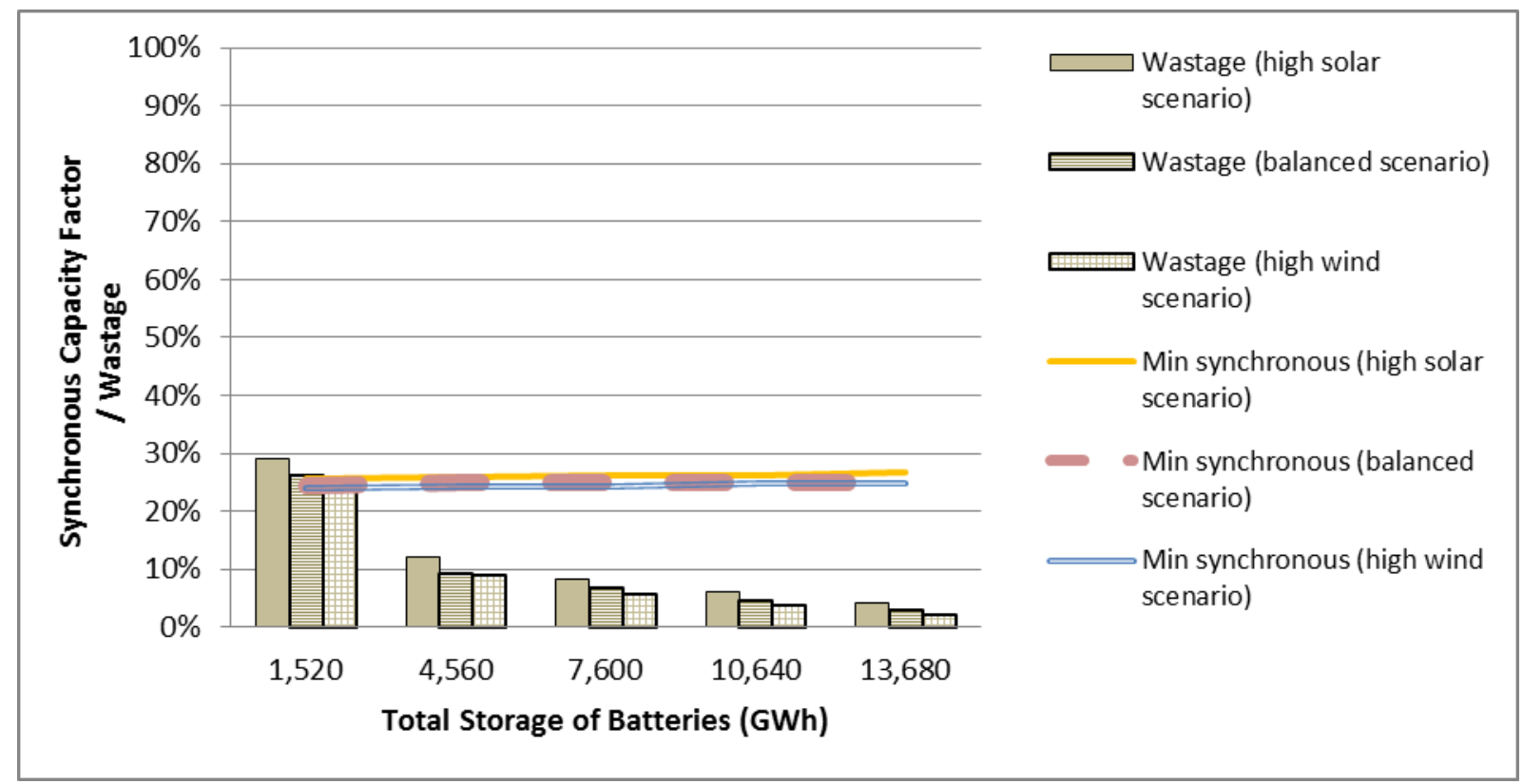

Figure 6. Average synchronous capacity and electricity wastage as a percentage of production for energy demand scenario B. The minimum synchronous generation that would be achieved if all renewable energy resource turbines were run in "synchronous condenser mode" is also shown 


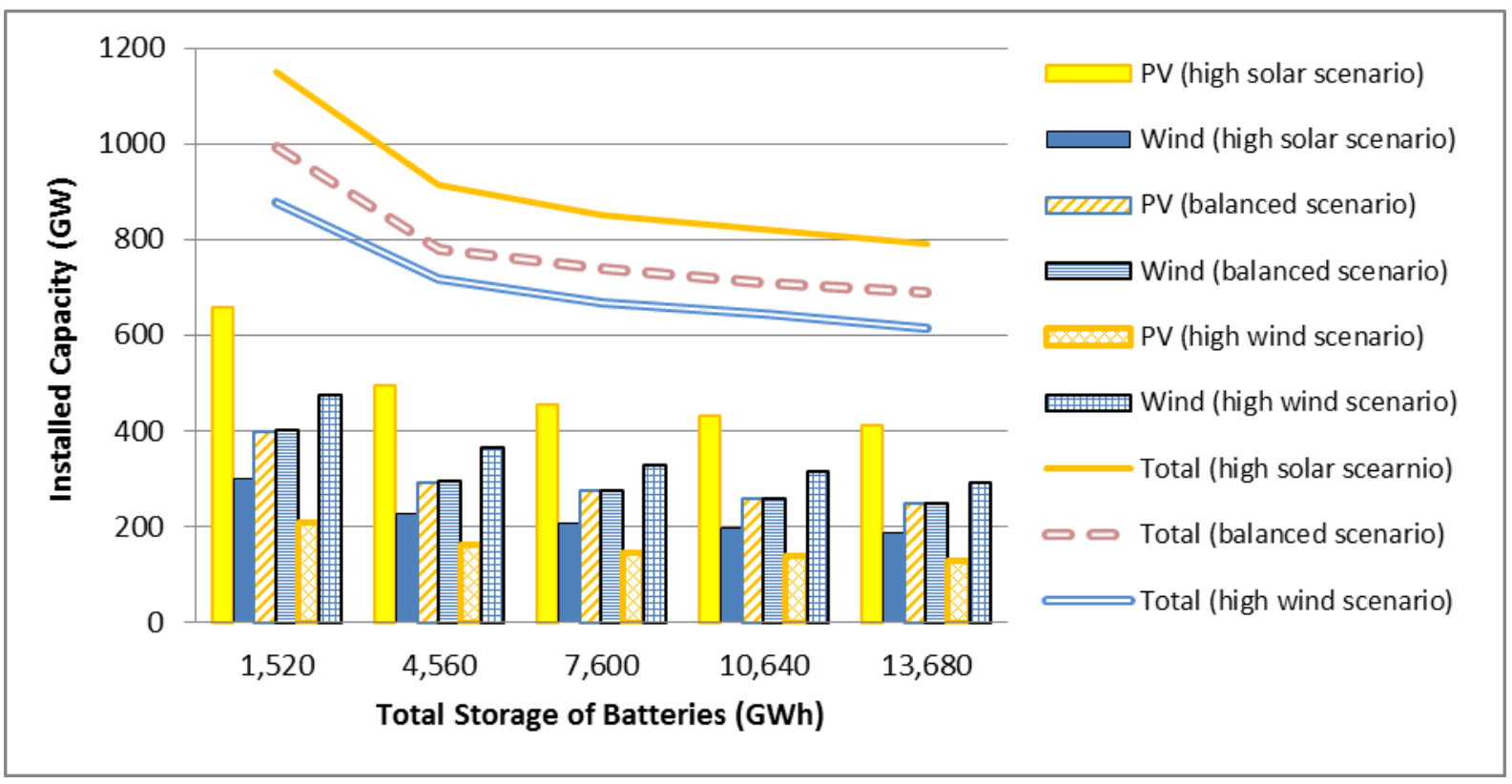

Figure 7. Required solar and wind installed capacity for scenario C (present day electricity consumption levels), for different storage capacities.

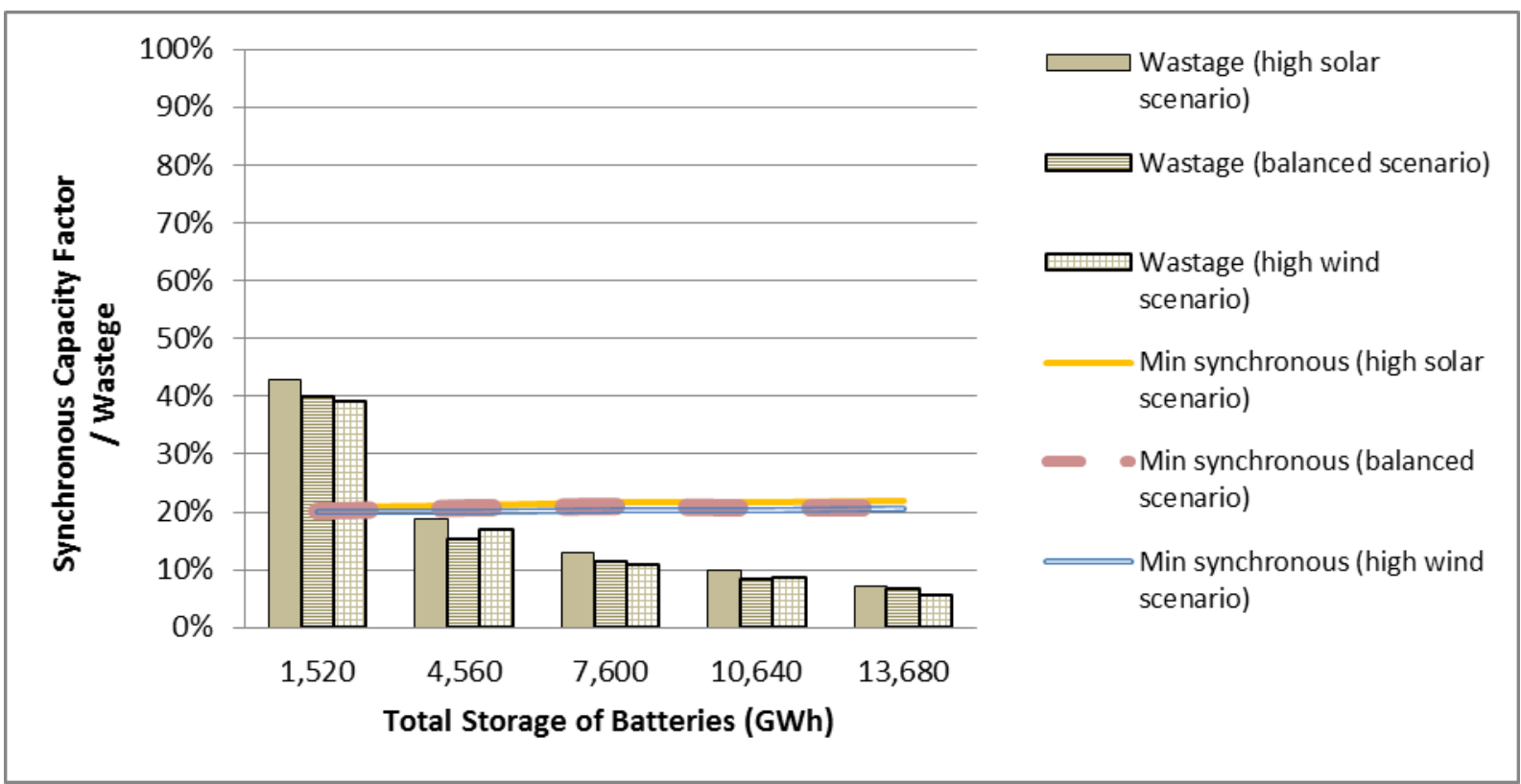

Figure 8. Average synchronous capacity and electricity wastage as a percentage of production for energy demand scenario $\mathrm{C}$. The minimum synchronous generation that would be achieved if all renewable energy resource turbines were run in "synchronous condenser mode" is also shown 


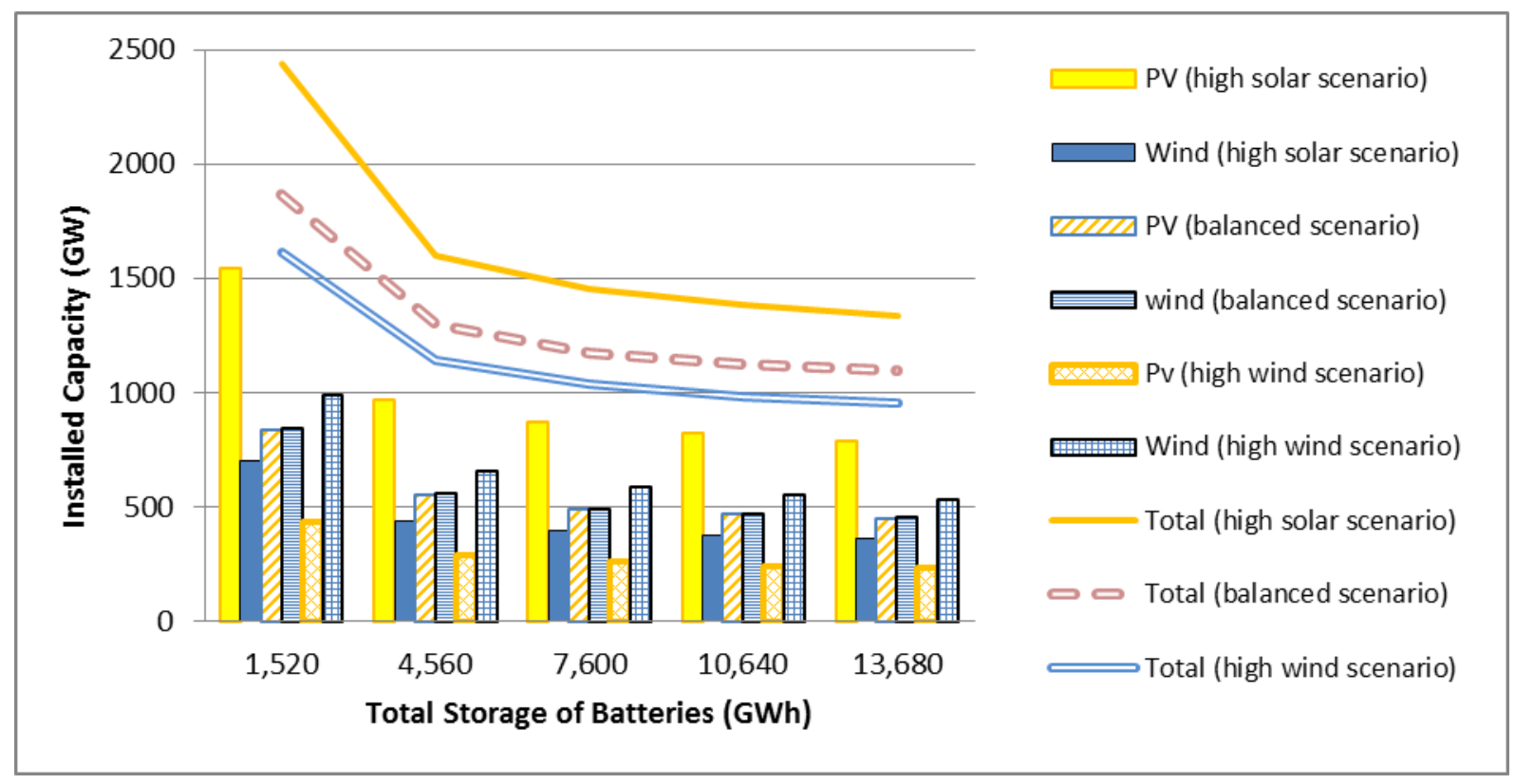

Figure 9. Required solar and wind installed capacity for scenario D (present day electricity consumption levels), for different storage capacities.

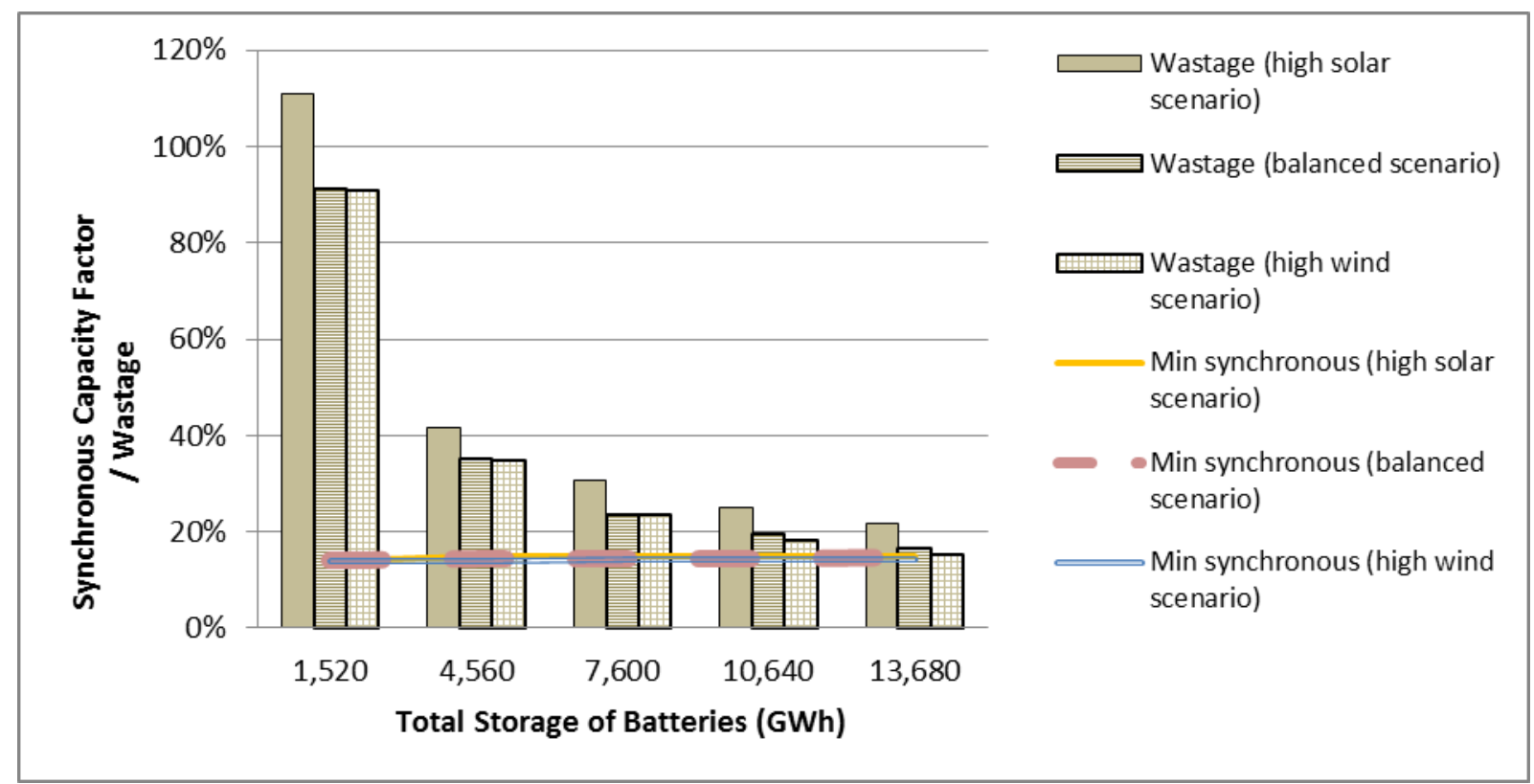

Figure 10. Average synchronous capacity and electricity wastage as a percentage of production for energy demand scenario D. The minimum synchronous generation that would be achieved if all renewable energy resource turbines were run in "synchronous condenser mode" is also shown. In this case, wastage is greater than the amount of electricity consumed, indicating that the installed capacity is so vast that in many instances more of it will be generated that can be possibly consumed or stored (in other words, a very inefficient system) 


\section{Overcoming wastage and synchronous generation issues}

There are a number of alternative storage technologies that could be explored for further cost-reduction on the production side or further expansion of variable renewable energy technologies. Some of these technologies are grid-scale, such as pumped hydro power, but this is considered to be at or close to its practical limit in Japan at present. One widely considered alternative technology is hydrogen - which can also potentially compete with electric vehicles as part of the transportation fleet. Hydrogen has the advantage of being a non-carbon energy carrier that can be produced from electrolysis of water (in this case) or from a variety of other energy sources, and can be used as longer-term or seasonal storage (in comparison to batteries which tend to be utilized for operations requiring a shorter storage period). Japan has a significant long term government-led industrial development program for hydrogen, with major automotive, energy and industrial manufacturers being involved [55-57]. Hydrogen has been widely examined as a method to smooth the variability of intermittent renewables $[58,59]$, and its flexibility for stationary and mobile applications, as well as the diversity of sources, has been seen as attractive.

There are a number of major challenges to hydrogen for balancing energy supply and demand. One of the key barriers is the round-trip efficiency of electrolysis, storage and utilization of hydrogen - for example, standard alkaline electrolysis has an efficiency of around $80 \%$, storage requires different energy inputs depending on the type of hydrogen storage, then the re-conversion of hydrogen to electricity through a high efficiency fuel cell is around 60\% efficient at best - even neglecting the storage, this is an efficiency of less than $50 \%$. Compare this to pumped hydro (80-90\% for the pumping then $\sim 95 \%$ for generation giving around 70-80\% round-tripor batteries (potentially greater than $90 \%$ for $\mathrm{Li}$-ion chemistries [60] or around $70-80 \%$ for lead acid batteries [61]). So while hydrogen may be useful for long-term 
storage, there are other technologies that will be more efficient in many cases. The other current issue with hydrogen is the cost - of all elements of the supply chain. While the price of fuel cells and electrolysers will reduce with sales volumes increases, the current widespread largescale usage is not financially viable.

Regarding batteries themselves, it is important to note that the required capacity of batteries in even the lowest assumption (1500 GWh) would require an enormous increase in current mining and manufacturing capacity in order to fulfil by 2030. While lithium ion battery production has been rapidly ramping-up, there was only around $30 \mathrm{GWh}$ production capacity in 2014 , with estimates that this will be around $130 \mathrm{GWh}$ by 2020 . At 2020 rates, that would require the whole world's production capacity over 10 years to meet the minimum battery requirement for Japan considered here. The rates of increase in capacity show potential to keep up with demand, but it is still stretching the limits of feasibility with the proposed scenarios, in which case hydrogen as a substitute may be more attractive. In contrast, PV and wind turbines are feasible for the more modest scenarios, given that the world currently installs $\sim 75 \mathrm{GW}$ of PV panels and $\sim 60 \mathrm{GW}$ of wind turbines each year.

Currently, PV systems often operate in the maximum power tracking (MPPT) mode in order to generate the maximum amount of income, though as more renewable intermittent sources enter the grid there will be an increasing operational demand for PVs to participate in power system frequency regulation [62]. Within the framework of frequency regulation, there are typically three approaches that can be used to reduce the fluctuation in PV power output [63], incluing installing and operating an energy storage system (ESS) while keeping PVs in MPPT mode, installing and operating dump load banks to absorb surplus energy, or operating PV in power dispatch mode using deliberate curtailment strategies, which is probably the most cost-effective strategy. A number of authors have investigated the technical feasibility of such systems, and it appears that they are indeed possible [62-64]. Thus, it is likely that in the 
future PV systems will likely have to go from operating in the maximum power point tracking mode (maximizing their income) to also participate in power system frequency regulation. This might make these systems slightly less profitable, but as the cost of PV panels continues to decrease it is likely that such decreases in financial efficiency will quickly be overcome by technological improvements.

\section{Conclusions}

The present paper simulated what future $100 \%$ renewable energy scenarios might look like for the case of Japan, focusing on the feasibility of such systems and the issue of synchronous generation. Such a model would have to be further developed and fine-tunes, but could become the backbone of a future electricity grid, by predicting (through forecasted meteorological data) the amount of electricity that would be produced, and highlighting issues in advance of them happening.

It is clear that if significant energy savings can be made and, through increases in energy efficiency throughout the country, $100 \%$ renewable energy electricity mixes can be achieved. However, scenarios where electricity demand is kept constant or increases, to deal with expected increases in the uptake of electric vehicles, would pose a challenge to conventional grid systems. To overcome this it is clear that there will be a need to implement smart grid systems, make sure that there is substantial amount of electricity batteries present, and arguably go for higher uptakes in PV power (as opposed to going for wind-intensive scenarios, which are probably unfeasible for the case of Japan). It is also likely that such systems will require the use of hydrogen storage, so that the extra electricity produced during some times of the year can be used during the winter and summer seasons. Finally, the present simulations also highlighted that PV systems will likely have to go from operating in the maximum power point tracking mode (maximizing their income) to also participate in power system frequency 
regulation. This will require some adjustments, but current technology indicates that such systems are feasible.

It worth pointing out that while the present paper was written on a Japanese perspective, similar electricity grids could be achieved in other countries. Essentially, if an isolated grid can achieve a $100 \%$ penetration of renewables, other more connected grids (such as those of European countries) can succeed in smoothening intermittent energy sources through the use of interconnections, batteries and hydrogen storage.

\section{References}

1. Mori et al., 2011. Tohoku Earthquake Tsunami Joint Survey Group. Nationwide Post Event Survey and analysis of the 2011 Tohoku Earthquake Tsunami, Coastal Engineering Journal, JSCE 54 (1).

2. Asahi Shimbun. Editorial: Why wait for the election? Abe should address nuclear power issues. Asahi Newspaper 2013, $19^{\text {th }}$ February. <http://ajw.asahi.com/article/views/editorial/AJ201302190028> [February 2013].

3. IEEJ. Short-term energy supply and demand outlook for Japan: analysis on scenarios through FY2013. The Institute of Energy Economics of Japan 2012.

4. Portugal-Pereira J, Troncoso Parady G, Castro Dominguez B. Japan's energy conundrum Post-Fukushima scenarios from a life cycle perspective. Energy Policy 2013.

5. METI

Energy

White

Paper. http://www.meti.go.jp/english/report/downloadfiles/2017_outline.pdf. Accessed 25 ${ }^{\text {th }}$ Nov 2017

6. Murakami, 2015. Outlook and challenges for nuclear power generation 2016. $42^{\text {nd }}$ forum on research works, the institute of energy economics. Japan 
7. UNFCCC (2015) Submission of Japan's Intended Nationallly Determined Contribution (INDC)

http://www4.unfccc.int/Submissions/INDC/Published\%20Documents/Japan/1/20150717_Japa n's\%20INDC.pdf Accessed 30 April 2017

8. IDDRI (2015) Beyond the Numbers: Understanding the Transformation Induced by INDCs www.iddri.org/Publications/Collections/Analyses/MILES\%20report.pdf Accessed 30 April 2017

9. EEC. [エネルギー・環境に関する選択肢] [Enerugii kankyou ni kan suru sentakushi] [Alternatives on energy and the environment] (in Japanese). Energy and Environment Council. National Policy Unit. Government of Japan. 2012.

10. METI. Review of Japan's Energy Policy. Ministry of Energy, Trade, and Industry. 2013. <http://www.meti.go.jp/english/policy/energy_environment/review/> [May 2013].

11. Hong S, Bradshaw CJA, Brook BW. Evaluating options for the future energy mix of Japan after the Fukushima nuclear crisis, Energy Policy 2013; 56, 418-424.

12. McLellan BC, Zhang Q, Utama NA, Farzaneh H, Ishihara KN. Analysis of Japan's post-Fukushima energy strategy, Energy Strategy Reviews 2013; 1-9.

13. Zhang Q, McLellan BC, Tezuka T and Ishihara KN. Economic and environmental analysis of power generation expansion in Japan considering Fukushima nuclear accident using a multi-objective optimization model. Energy 2012; 44:986-995.

14. Takase K, and Suzuki T. The Japanese energy sector: Current situation, and future paths. Energy Policy 2010.

15. “2050 Japan Low-Carbon Society” Scenario Team. Japan Scenarios towards Low-Carbon Society, National Institute for Environmental Studies (NIES), Kyoto University, Ritsumeikan University and Mizuho Information and Research Institute. 2009.

16. Esteban M, Zhang Q, Utama A, Tezuka T and Ishihara KN. Methodology to Estimate the Output of a Dual Solar-Wind Renewable Energy System in Japan, Energy Policy 2010; 38: 7793-7802. 
17. Energy Rich Japan Report. 2003. <www.energyrichjapan.info> (accessed July 2010).

18. Esteban, M. and Portugal-Pereira (2014) "Post-Disaster Resilience of a 100\% Renewable Energy System in Japan”, Energy, vol. 68, issue C, pages 756-764

19. Tsuchiya, H. (2012) Electricity supply largely from solar and wind resources in Japan. Renewable energy, 48, 318-325

20. Heard, B. P., Brook, B. W., Wigley, T.M.L. and Bradshaw, C.J.A. (2017) Burden of proof: A comprehensive review of feasibility of $100 \%$ renewable-electricity systems. Renewable and Sustainable Energy Reviews 76, 1122-1133.

21. Lund $\mathrm{H}$ and Mathiesen BV . Energy system analysis of $100 \%$ renewable energy systems the case of Denmark in years 2030 and 2050, Energy 2009; 34, 524-531.

22. Lin SY and Chen JF. Distributed optimal power flow for smart grid transmission system with renewable energy sources. Energy 2013; 56: 184-192.

23. Zhang Q, Ishihara KN, Mclellan BC, Tezuka T. Scenario analysis on future electricity supply and demand in Japan. Energy 2010; 38: 376-385.

24. Meeus L, Purchala K, and Belmans R. Market opening: The Norned submarine HVDC Cable. Proc. of Power-Gen Europe 2005.

25. Nikkei Electronics. Smart grid ON! - Next generation electricity gird based on battery and sensor , 2009;10.19, 30-52 [in Japanese].

26. Yokoyama A. An introduction to smart grid. 2009, [In Japanese] <http://www.syl.t.u-tokyo.ac.jp/S> (accessed December 2009).

27. Hall P J and Bain E J. Energy-storage technologies and electricity generation, Energy policy 2008; 36 (12), 4352-4355.

28. Yoda $\mathrm{S}$ and Ishihara K. Global energy prospects in the 21 st century: a battery-based society, J. of Power Sources 1997; 68(1),3-7.

29. Yang C. Hydrogen and electricity: parallels, interactions and convergence, Int. J. of Hydrogen Science 2008; 33: 1977-1994. 
30. Sherif SA, Barbir F and Veziroglu TN. Wind energy and the hydrogen economy-review of the technology, Solar Energy 2005; 78, 647-660.

31. Gutierrez-Martın F, Garcı-De Marı JM, Baıri A and Laraqi N, . Management strategies for surplus electricity loads using electrolytic hydrogen, Int. J. of Hydrogen Energy 2009; 34, $8468-8475$

32. Levene JI, Mann MK, Margolis RM.and Milbrandt A. An analysis of hydrogen production from renewable electricity sources, Solar Energy 2007; 81, 773-780.

33. Giaouris et al. Performance investigation of a hybrid renewable power generation and storage system using systemic power management models. Energy 2013; 61:621-635.

34. FEPC. Electricity Statistic Information. Federation of Electricity Power Companies 2013. <http://www5.fepc.or.jp/tok-bin-eng/kensaku.cgi > (accessed May 2013).

35. ANRE. Feed-In Tariff scheme in Japan. Agency for Natural Resources and Energy. Ministry of Economy, Trade and Industry. Government of Japan. 2012.

36. Esteban M, Zhang Q, Utama A. Estimation of the Energy Storage Requirement of a Future 100\% Renewable Energy System in Japan, Journal of Energy Policy 2012; 57, 22-31.

37. Australian Enery Market Operator Ltd. (2013) 100 per cent renewable study- modelling outcomes. New South Wales.

38. METI. Electricity Business Act. Act No. 87. Ministry of Economy, Trade and Industry. Government of Japan. 2005.

39. ANRE. Cabinet Decision on the Policy on Electricity System Reform. Agency for Natural Resources and Energy. Ministry of Economy, Trade and Industry. Government of Japan. 2013.

40. FEPC. Energy and Electricity. Federation of Electric Power Companies of Japan. 2010. <http://www.fepc.or.jp/english/energy_electricity/optimal_combination/index.html> (accessed February 2010).

41. Yumae, S. (2016) Japan's overbuilt solar market waiting for a new dawn. Nikkei Asian Review. http://asia.nikkei.com/Business/Trends/Japan-s-overbuilt-solar-market-waiting-for-new-dawn Accessed 7th December 2016 
42. JPEA (2016). http://www.fit.go.jp/statistics/public_sp.html Accessed $20^{\text {th }}$ November 2017

43. Japanese National Institute of Population and Social Security Research. Population Projections for Japan (January 2012): 2011 to 2060. 2012.

44. Shogo, K. (2016) Sustainability Field Exercises in rural Areas: Applying the Community Marginalization Framework to Examine Qualitative Changes in Rural Communities. In Sustainability Science: Field Methods and Exercises. Esteban. M., Akiyama, T., Chen, C. Ikeda, I. and Mino, T. (eds). Springer Int., Switzerland.

45. JCER. The $39^{\text {th }}$ Medium-Term Economic Forecast (2012FY-2025FY): Japan's Changes in Industrial Structure and Economic Growth. Tokyo. Japan Centre for Economic Research. 2013.

46. Zhang, Q., Tezuka, T., Ishihara, K., Esteban, M., Utama, N.A. 2009. Study on zero- carbon electricity system in Japan using a proposed optimization model, Proceedings of International Symposium on Sustainable Energy and Environ- mental Protection (ISSEEP) Yogyakarta, Indonesia, 23-26 September 2009.

47. ANRE. エネルギー白書 [Enerugii Shiroi] [Energy White Book] [in Japanese]. Agency for Natural Resources and Energy. 2009.

48. FEPC. Electricity Statistic Information. Federation of Electricity Power Companies 2013. <http://www5.fepc.or.jp/tok-bin-eng/kensaku.cgi> (accessed May 2013).

49. FEPC. Energy and Electricity. Federation of Electric Power Companies of Japan. 2010.

50. AMeDAS (Automated Meteorological Data Acquisition System of the Japan Meteorological Agency) <http://www.jma.go.jp/jp/amedas> (accessed October 2013)

51. Bricker, J. D., Esteban, M., Takagi, H. and Roeber, V. (2017) "Economic Feasibility of Tidal Stream and Wave Power in Post-Fukushima Japan”. Renewable Energy 114, 32-45.

52. Nishikawa Y, Tezuka T, Kita H and Kang MS. Effect of a Photovoltaic Power Generation System on Power Plant Mix. IFAC Energy Systems, Management and Economics, Tokyo, Japan. 1989. 
53. Stiebler M. ( Wind Energy Systems for Electric Power Generation. Springer Series, ISBN: 978-3-540-68762-7. 2008.

54. Denholm P et al., The Role of Energy Storage with Renewable Electricity Generation, National Renewable Energy Laboratory, Technical Report NREL/TP-6A2-47187.

55. FCB, Hydrogen Town Project under way in Japan with pipeline network. Fuel Cells Bulletin 2011, $2011(2), 8-9$.

56. Lee, D.-H., Development and environmental impact of hydrogen supply chain in Japan: Assessment by the CGE-LCA method in Japan with a discussion of the importance of biohydrogen. International Journal of Hydrogen Energy 2014, 39 (33), 19294-19310.

57. Mitsugi, C.; Harumi, A.; Kenzo, F., WE-NET: Japanese hydrogen program. International Journal of Hydrogen Energy 1998, 23 (3), 159-165.

58. Clarke, D. P.; Al-Abdeli, Y. M.; Kothapalli, G., The impact of renewable energy intermittency on the operational characteristics of a stand-alone hydrogen generation system with on-site water production. International Journal of Hydrogen Energy 2013, 38 (28), 12253-12265.

59. Mori, M.; Jensterle, M.; Mržljak, T.; Drobnič, B., Life-cycle assessment of a hydrogen-based uninterruptible power supply system using renewable energy. The International Journal of Life Cycle Assessment 2014, 19 (11), 1810-1822.

60. Hua, A. C. C.; Syue, B. Z. W. In Charge and discharge characteristics of lead-acid battery and LiFePO4 battery, The 2010 International Power Electronics Conference - ECCE ASIA -, 21-24 June 2010; 2010; pp 1478-1483.

61. Rydh, C. J., Environmental assessment of vanadium redox and lead-acid batteries for stationary energy storage. Journal of Power Sources 1999, 80 (1-2), 21-29.

62. Xin, H., Liu, Y., Wang, Z. and Gan, D. 2013 A New Frequency Regulation Strategy for Photovoltaic Systems Without Energy Storage. IEEE Transactions on Energy Conversion,, Vol. 4, No. 4., 985-993

63. Omran, W. A., Kazerani, M., Salama, M. M. A. 2011 Investigation of Methods for Reduction of Power Fluctuations Generated from Large Grid-Connected Photovoltaic Systems. IEEE 
Transactions on Energy Conversion, Vol 26, No. 1, 318-327

64. Basha, H., Venkatesh, P. 2015. Control of Solar Photovoltaic (PV) Power Generation in Grid-Connected and Islanded Microgrids. Int Journal of Engineering Research and General Science. Vol3. (2), 121-141. 